\title{
Buchbesprechung
}

Irmy Rey-Stocker

\section{Anfang und Ende des menschlichen Lebens aus der Sicht der Medizin und der drei monotheistischen Religionen Judentum, Christentum und Islam}

Karger, Basel, 2006

Gebunden, XIV + 284 S.; 13 Abb.

CHF 48.-/EUR 34.50/USD 43.75

ISBN 978-3-8055-8012-0

Das neu erschienene Buch von Dr. Irmi Rey-Stocker über «Anfang und Ende des menschlichen Lebens» beschäftigt sich mit einem wichtigen Problem, sozusagen einer «Urfrage» der Menschheit.

Menschen haben die Fähigkeit, sich nicht nur mit sich selbst zu beschäftigen, sondern auch über die Urfragen ihrer Existenz wie den Anfang und das Ende des Lebens nachdenken zu können. Hierbei berühren sich Philosophie, Kunst und Kultur. Diese Bereiche, die noch bei Asklepios eng miteinander verbunden waren, werden heute in unserer arbeitsteiligen Gesellschaft von verschiedenen Fachleuten und Disziplinen vertreten, eben Spezialisten für die scheinbar so sauber getrennten «Fächer». Umso bewundernswerter sind die «Grenzgänger» unter uns, die es wagen, sogar ohne die primäre Legitimation durch Hochschulausbildung oder Diplome, in Nachbargebiete vorzudringen und Antworten mit Hilfe der anderen Wissenschaften auf interessante und ungelöste Fragen zu finden. Eine solche mutige Persönlichkeit ist
Frau Kollegin Irmi Rey-Stocker, die nach einem interessanten Berufsleben in verschiedensten Funktionen des Medizin-Betriebes sich nun in einem Buch mit der wohl fundamentalsten Frage unseres Daseins beschäftigt, nämlich der Frage, was Leben überhaupt ist und was Anfang und Ende determiniert.

Die Autorin stellt sehr mutige Fragen, z.B. worauf die drei monotheistischen Religionen ihre Aussage zurückführen, dass der eine Gott der Schöpfer des Lebens ist. Zentral und ausführlich wird behandelt, worin sich die Religionen Judentum, Islam und Christentum in ihrer Ethik unterscheiden. Seit jeher haben sich diese Religionen mit den Fragen um den Anfang und das Ende des menschlichen Lebens beschäftigt, aber es ist legitim zu fragen, ob die Antworten noch aktuell sind im Hinblick auf die Fortschritte in der Medizin.

Man spürt beim Lesen des Buches von Dr. Rey-Stocker, die sowohl in der Schweiz wie in den USA und Israel wissenschaftlich und ärztlich gearbeitet hat, dass sie ihre Untersuchungen und ihr Studium der Quellen sehr sorgfältig durchgeführt und in vielen Gesprächen reflektiert hat. Die religiösen Aspekte werden ebenso klar analysiert wie die medizinischen und philosophischen Grundlagen - bis zurück zum antiken Griechenland.

Wegen des interdisziplinären Charakters richtet sich das Buch an einen weiten Leserkreis, aber speziell Ärzte werden für ihre tägliche Arbeit bei der Betreuung von Patientinnen mit unterschiedlichen religiös-weltanschaulichen Hintergründen vom Lesen profitieren. Man kann dem wertvollen Buch von Frau Dr. Rey-Stocker nur eine grosse Verbreitung und den gewünschten Erfolg wünschen.

Wolfgang Holzgreve, Basel

\section{KARGER}

(C) 2007 S. Karger AG, Basel

Fax +41613061234 